\title{
ANAP

\section{A EDUCAÇÃO AMBIENTAL SEGUNDO OS PLANOS MUNICIPAIS DE GESTÃO INTEGRADA DE RESÍDUOS SÓLIDOS DA MICRORREGIÃO DE JABOTICABAL - SP}

Environmental Education according to the Municipal Plans of Integrated Management of Solid Residues of the Micro Region of Jaboticabal - SP

La Educación Ambiental según los Planes Municipales de Gestión Integrada de Resíduos Sólidos de la Microrregión de Jaboticabal - SP

Lívia Martinez Brumatti Mestre em Geografia, UNESP, Brasil. livia.brumatti@hotmail.com

Patricia Lopes Freire Pupin Graduada em Administração, FCETM, Brasil. patricialopesfreire@hotmail.com

Ana Claudia Giannini Borges Professora Doutora, UNESP, Brasil. agiannini@fcav.unesp.br 


\section{RESUMO}

A Educação Ambiental, institucionalizada pela Lei 9.795/99 que é reconhecida como Política Nacional de Educação Ambiental, é um instrumento fundamental para o conhecimento e a perpetuidade das ações definidas pela Política Nacional de Resíduos Sólidos (PNRS). Na Política Nacional de Educação Ambiental estão elencadas as atividades propostas para a Educação Ambiental que ressoam na PNRS e, consequentemente, nos Planos Municipais de Gestão Integrada de Resíduos Sólidos (PMGIRS). Assim, este artigo se propôs a identificar e analisar as abordagens sobre Educação Ambiental, nos PMGIRS da Microrregião de Jaboticabal, à luz das atividades descritas no artigo $8^{\circ}$ da Lei 9.795/99. Os municípios são: Bebedouro, Guariba, Jaboticabal, Monte Alto, Pitangueiras e Taquaritinga. Identificou-se que nenhum município atende integralmente, nos textos de seus Planos, aos preceitos da Política Nacional de Educação Ambiental sobre Educação Ambiental e, por isso, a aplicação e perpetuidade das ações da PNRS pode estar comprometida.

PALAVRAS-CHAVE: Educação Ambiental. PNRS. PMGIRS da Microrregião de Jaboticabal.

\section{ABSTRACT}

The Environmental Education, institutionalized for the Low 9,795/99 which is recognized as National Politics of Environmental Education, is a fundamental instrument for the knowledge and the perpetuity of the actions defined by National Politics of Solid Residues (NPSR). There are some proposed activities for Environmental Education listed at National Politics of Environmental Education that resonate in NPSR and, consequently, in the Municipal Plans of Integrated Management of Solid Residues (MPIMSR). Thus, this article aimed to identify and analyze the approaches on Environmental Education in the MPIMSR of Jaboticabal micro region, according to the activities described in Article 8 of the Low 9,795/99. The municipalities are: Bebedouro, Guariba, Jaboticabal, Monte Alto, Pitangueiras and Taquaritinga. It has been identified that no municipality includes integrally, in the texts of their Plans, the precepts of National Politics of Environmental Education on Environmental Education and, therefore, the application and perpetuity of NPSR actions may be impaired.

KEY-WORDS: Environmental Education. NPSR. MPIMSR of Jaboticabal Microrregion.

\section{RESUMEN}

La Educación Ambiental, institucionalizada por la Ley 9.795/99 que es reconocida como Política Nacional de Educación Ambiental, es un instrumento fundamental para el conocimiento y la perpetuidad de las acciones definidas por la Política Nacional de Resíduos Sólidos (PNRS). En la Política Nacional de Educación Ambiental se enumeran las actividades propuestas para la Educación Ambiental que resuenan en la PNRS y, por consiguiente, en los Planes Municipales de Gestión Integrada de Residuos Sólidos (PMGIRS). Así, esto artículo tuvo como objetivo identificar y analizar los abordajes sobre Educación Ambiental en los PMGIRS de la Microrregión de Jaboticabal, a la luz de las actividades descritas en el artículo 8o de la Ley 9.795/99. Los municipios son: Bebedouro, Guariba, Jaboticabal, Monte Alto, Pitangueiras y Taquaritinga. Se identificó que ningún municipio cumple en su totalidad, en los textos de sus Planes, los preceptos de la Política Nacional de Educación Ambiental en educación ambiental y, por lo tanto, la aplicación y la perpetuidad de las acciones de PNRS pueden verse comprometidas.

PALABRAS CLAVE: Educación Ambiental. PNRS. PMGIRS de la Microrregión de Jaboticabal. 


\section{INTRODUÇÃO}

A Política Nacional de Resíduos Sólidos (PNRS), instituída pela Lei $\mathrm{n}^{\circ}$ 12.305/10 (BRASIL, 2010a), é um marco regulatório que norteia a questão dos resíduos sólidos no Brasil dispondo diretrizes referentes à gestão integrada e ao gerenciamento dos mesmos. Além disso, orienta inúmeros aspectos desta cadeia, que vai desde a correta destinação até a responsabilização dos geradores.

Nesse ínterim, a PNRS elenca um tema de suma importância para a sua constituição e perpetuidade: a educação ambiental (EA) (BRASIL, 2010a, art. $8^{\circ}$ ). Esta, pelo texto da PNRS, objetiva o "aprimoramento do conhecimento, dos valores, dos comportamentos e do estilo de vida relacionados com a gestão e o gerenciamento ambientalmente adequado de resíduos sólidos." (BRASIL, 2010b, art. 77). Este objetivo deverá estar articulado à percepção de EA na Política Nacional de Educação Ambiental, regulada pela Lei $n^{\circ}$ 9.795, de 27 de abril de 1999 (BRASIL, 1999). No artigo $1^{\circ}$, desta Política, a EA é definida como processos, onde "o indivíduo e a coletividade constroem valores sociais, conhecimentos, habilidades, atitudes e competências voltadas para a conservação do meio ambiente, bem de uso comum do povo, essencial à sadia qualidade de vida e sua sustentabilidade." (BRASIL, 2009, art. 1ํ).

Dessa forma, a EA, tanto na Política Nacional de Educação Ambiental, quanto no texto da PNRS, tem como finalidade: oportunizar condições para o controle social tanto do meio ambiente como um todo e, especificamente, dos resíduos sólidos; proporcionar conhecimento; gerar valores sociais; avaliar, pelo estilo de vida e comportamento da população, as atitudes e aptidões dos mesmos para a conservação do meio ambiente, entre outros.

Jacobi (2003, p. 197) situa a educação ambiental como uma "educação para a cidadania, configurando-a como elemento determinante para a consolidação de sujeitos cidadãos", colocando todos como "corresponsáveis" pela qualidade de vida. O autor afirma que "a educação ambiental deve ser acima de tudo um ato político voltado para a transformação social." (2003, p. 196). E, nesse sentido, a Política Nacional de Educação Ambiental é uma política pública capaz de interferir socialmente.

Esta Política institui ações que devem ser inter-relacionadas na educação em geral e na educação escolar (BRASIL, 1999, art. $8^{\circ}$ ): I - capacitação de recursos humanos; II desenvolvimento de estudos, pesquisas e experimentações; III - produção e divulgação de material educativo; IV - acompanhamento e avaliação. Especificamente quanto a estes pontos, deve-se apresentar o detalhamento da Lei para os dois primeiros. Para a capacitação de recursos humanos estabelece-se como necessário: "incorporação da dimensão ambiental na formação, especialização e atualização dos educadores de todos os níveis e modalidades de ensino". O mesmo deve ocorrer com os profissionais de todas as áreas, pois estes devem ser capazes de realizar gestão ambiental. É importante considerar que, na Lei, não basta formar os profissionais, especializando-os, é essencial que isto ocorra de forma continuada. (BRASIL, 1999 , art. $8^{\circ}, \S 2^{\circ}$ ). 


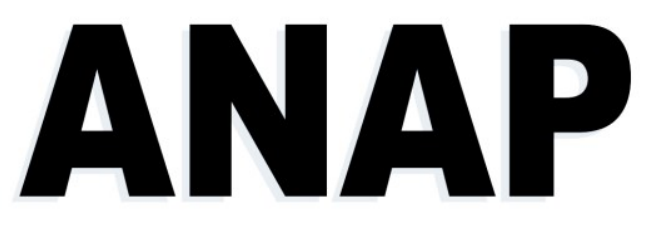

Brasil

ISSN 1984-3240

v. 9, n. 14

Para o desenvolvimento de estudos, pesquisas e experimentações estabelece-se como ações:

I - o desenvolvimento de instrumentos e metodologias, visando à incorporação da dimensão ambiental, de forma interdisciplinar, nos diferentes níveis e modalidades de ensino;

II - a difusão de conhecimentos, tecnologias e informações sobre a questão ambiental;

III - o desenvolvimento de instrumentos e metodologias, visando à participação dos interessados na formulação e execução de pesquisas relacionadas à problemática ambiental;

IV - a busca de alternativas curriculares e metodológicas de capacitação na área ambiental;

$\mathrm{V}$ - o apoio a iniciativas e experiências locais e regionais, incluindo a produção de material educativo;

$\mathrm{VI}$ - a montagem de uma rede de banco de dados e imagens, para apoio às ações enumeradas nos incisos I a V. (BRASIL, 1999, art. $8^{\circ}$, $\S 2 \div$ ).

Andrade et al. (2014, p. 825) abordam que, para a EA ter legitimidade, se faz necessário políticas públicas que contemplem a "sociobiodiversidade local" e que, se houver apenas formulações distantes da realidade local os conteúdos "não refletem o processo de sua construção e nem serão traduzidos nas ações que decorrem delas". Dessa forma, para a devida aplicação da Política Nacional de Educação Ambiental assim como da PNRS, a esfera Federal articula-se integradamente com os Estados e, especialmente, com os Municípios.

Nesse sentido, a PNRS estabelece a elaboração de Planos Municipais de Gestão Integrada de Resíduos Sólidos (PMGIRS), obrigatoriamente aos Municípios com mais de 20.000 habitantes (BRASIL, 2010a, art. 19), já que estes são o território objeto de administração do gerenciamento de resíduos sólidos.

Os PMGIRS devem abordar a EA nos moldes da Política Nacional de Educação Ambiental, elaborando "programas e ações de educação ambiental que promovam a não geração, a redução, a reutilização e a reciclagem de resíduos sólidos" (BRASIL, 2010a, art. 19).

Quanto às práticas e atividades que devem ser conduzidas no processo de EA, Andrade et al. (2014, p. 827) abordam ainda que "[...] o processo pedagógico que gerou a política não é, necessariamente, refletido na/e difundido pelos conteúdos da política pública produzida." Complementando esta afirmação, os autores destacam que as "práticas de EA construídas à luz de uma política que tenha um conteúdo que estimule a participação e o diálogo incorporem tais características. Neste caso, o problema aparece na outra ponta, ou seja, a política que gerou as práticas não é refletida nelas." (2014, p. 827).

Percebe-se neste trecho a problematização em torno das políticas públicas que abrangem a temática da educação ambiental, isto é, mesmo que existam programas, projetos, normas e regulamentos adequados que exponham todas as etapas e processos a serem desenvolvidos 


\section{ANAP \\ Brasil \\ ISSN 1984-3240 \\ v. 9, n. 14}

em EA em determinado município, não há garantias de que os mesmos serão efetivados, sendo necessária a fiscalização da execução dos mesmos.

\section{OBJETIVOS}

Diante do exposto, o presente artigo objetiva identificar e analisar a abordagem feita pelos PMGIRS da microrregião de Jaboticabal - SP sobre a temática da educação ambiental e, se a mesma atende aos preceitos da PNRS e da Política Nacional de Educação Ambiental, mais precisamente às atividades descritas no artigo $8^{\circ}$ da última.

\section{METODOLOGIA / MÉTODO DE ANÁLISE}

Na tentativa de compreender a problemática da Educação Ambiental para as Políticas Públicas municipais, foram levantados seis Planos Municipais na microrregião de Jaboticabal - SP. Os municípios selecionados seguem o critério estabelecido a partir da limitação feita pela Lei 12.305/10, na qual aqueles municípios com menos de 20.000 habitantes são desobrigados a elaborar os Planos Municipais. Portanto, dos 17 municípios dessa microrregião apenas seis são obrigados a elaborar o Plano, sendo eles: Bebedouro, Guariba, Jaboticabal, Monte Alto, Pitangueiras e Taquaritinga.

Para acesso aos Planos Municipais dos municípios selecionados foram feitas pesquisas públicas com os órgãos e departamentos responsáveis pela pasta de resíduos sólidos. Com tais Planos em mãos, foram selecionadas todas as informações referentes à Educação Ambiental, para a realização de uma análise minuciosa sobre a abordagem de cada município sobre o tema.

Após pesquisa bibliográfica em leis, decretos e autores que abordam o assunto, obteve-se a problemática do artigo e os seguintes resultados e conclusões.

\section{RESULTADOS}

Articulando as atividades descritas no artigo $8^{\circ}$ da Política Nacional de Educação Ambiental com a temática proposta na PNRS, conforme esta última institui, obtiveram-se os seguintes resultados:

\section{Bebedouro}

O Plano de Saneamento dos Resíduos Sólidos Urbanos e Manejo de Resíduos do município de Bebedouro foi elaborado em conjunto com o município de Barretos - SP, na forma de um Consórcio Intermunicipal para Gestão Integrada de Resíduos Sólidos - SIGEINRES.

Neste Plano, a temática da Educação Ambiental aparece como dever essencial do Poder Público: 


\section{ANAP Brasil v. 9, n. 14}

(...) Cabe ao Poder Público "promover a educação ambiental em todos os níveis de ensino e a conscientização pública para a preservação do meio ambiente". A Educação Ambiental sozinha não é suficiente para resolver os problemas ambientais, mas é condição indispensável para tanto. A grande importância da Educação Ambiental é contribuir para a formação de cidadãos conscientes de seu papel na preservação do meio ambiente e, aptos para tomar decisões sobre as questões ambientais necessárias para o desenvolvimento sustentável. (2011, p. 65).

Para a efetivação da EA, o Plano estabelece que o SIGEINRES deverá: "instrumentalizar-se para acompanhar a promoção dos trabalhos de educação ambiental" de forma gradual; se envolver "em programas de educação e aprendizagem ambiental, com ênfase na questão de pré-seleção, reciclagem, reutilização e acondicionamento" dos resíduos sólidos (2011, p. 64); e, desenvolver uma "estrutura de comunicação, informação e mobilização social" (bidirecional). (2011, p.75).

Para tal, o Plano propõe: um programa envolvendo escolas municipais, associações e organizações, sob as temáticas da "minimização na geração de resíduos, a manutenção da limpeza das ruas de maneira racional, a segregação dos diversos tipos de resíduos na fonte para a sua posterior reciclagem", entendendo que estes são agentes multiplicadores de conscientização (2011, p.76); a utilização dos recursos de mídia para veiculação de campanhas (de massa) e mensagens educativas, como a inclusão de cartilhas, boletins, cartazes, jogos pedagógicos, lixeirinhas plásticas para utilização em veículos, adesivos, etc; e, a construção de um diálogo permanente com a população.

Além dessas ações, o Plano propõe a expansão da abrangência da coleta seletiva, com maior frequência de recolhimento, bem como a definição de um agente fiscalizador que garanta a credibilidade das ações.

O Plano estabelece as diretrizes, porém não informa como as mesmas serão realizadas nos municípios consorciados e o que cabe a cada um. Além disso, não deixa claro como serão elaborados os estudos, pesquisas e experimentações ditados pela Política Nacional de Educação Ambiental.

\section{Guariba}

No Plano Integrado de Gestão de Resíduos Sólidos Guaribense (PIGRSG) há uma afirmação de que existe "vasta legislação ambiental que estimula [...] o bom nível de entendimento e conscientização de sua população em função de Plano Municipal de Educação Ambiental em curso" (2014, p. 7). Ao mesmo tempo o Plano afirma ser seu objetivo reorganizar "todo o 


\section{ANAP Brasil v. 9, n. 14}

processo, ajustando os vários tipos de resíduos, intensificando a Educação Ambiental em todas as frentes; melhorando e acelerando a prospeç̧ão de dados" $(2014$, p. 8). As duas afirmativas são confusas, uma vez que na primeira, fala-se de uma "vasta legislação ambiental" sem nem mesmo mencionar um exemplo e sem se considerar o fato de que a existência de determinada legislação não garante o conhecimento da mesma pela população, muito menos serve de entendimento e conscientização da população frente à Educação Ambiental.

Em relação à segunda afirmativa, as informações são muito vagas, e quando se fala em intensificação da EA em todas as frentes, não se conceitua em nenhum momento o que o poder público entende como EA, nem quais são as frentes de atuação do mesmo.

Algumas estratégias de ação são mencionadas no Plano:

- "Implementação de iniciativas de gestão de resíduos e compras sustentáveis nos órgãos da administração pública" (2014, p. 51);

- "Programas e ações de educação ambiental voltada para a não geração, redução, reutilização e reciclagem de resíduos sólidos" (2014, p. 51);

- Desenvolvimento de um novo projeto de coleta seletiva (em razão da extinção da associação de reciclagem), com a realização de Campanhas de Educação Ambiental para separação correta dos resíduos recicláveis e destinação adequada;

- "Realização [contínua] de treinamentos e palestras de educação ambiental para multiplicadores (professores, lideranças comunitárias, técnicos da prefeitura, dentre outros)" (2014, p. 63);

- Envolver os catadores nas ações educativas para valorizar a figura do mesmo; e,

- Por fim, "os investimentos devem ser de ordem educacional, valorizando a situação que se encontra, enaltecendo os resultados obtidos e utilizar profundamente o espaço como ponto de apoio a Educação ambiental." (2014, p. 123).

Percebe-se, nessas diretrizes de ação, que os termos utilizados são abrangentes e pouco explicam o modo como cada um dos objetivos serão executados. Além disso, não há um procedimento metodológico definido. Assim posto, nenhum dos quatro itens do artigo $8^{\circ}$ da Lei 9.795/99 (BRASIL, 1999) foi abordado seguindo os critérios propostos.

\section{Jaboticabal:}

O Plano Municipal de Gestão Integrada de Resíduos Sólidos - Jaboticabal (PMGIRS Jaboticabal) faz referência à Lei 12.305 de 2010 e propõe alguns objetivos (Quadro 1) para a implementação da Educação Ambiental de acordo com a referida Lei.

\section{Quadro 1: Objetivos do Programa de Educação Ambiental do PMGIRS de Jaboticabal}

Entender a importância da destinação correta dos resíduos sólidos, reduzindo sua geração na fonte, reutilizando os materiais que possam ter utilidade e separando os que podem ser reciclados, dando um destino mais nobre para os resíduos; 


\section{ANAP

Colaborar para manutenção do ambiente urbano, através de ações que visem à diminuição dos resíduos descartados em locais inadequados, correta destinação e colaboração com o município com atitudes corretas; Salientar que, de acordo com a PNRS, o munícipe tem obrigação de separar os resíduos e dar o destino correto, sob pena de multa;

Ministrar cursos e oficinas de reuso de materiais, com o objetivo de transformá-los em materiais que podem ser reaproveitados como peças ornamentais, brinquedos, utensílios e demais objetos, com o propósito de poupar matéria-prima e trabalhar com o conceito de reutilização dos resíduos;

Promover visitas educacionais em locais cuja temática seja Resíduos Sólidos, Meio Ambiente e Ecoturismo;

Criar parceria com empresas geradoras de resíduos do tipo óleos e graxas, com o objetivo de conscientizar a população em geral ao descarte correto.

O programa de Educação Ambiental deverá ser direcionado à sociedade em geral, aos diversos atores sociais: professores, alunos, lideranças de bairros, ONG's, comerciantes, consumidores e demais munícipes, como acima citado, para que ocorra uma socialização do conhecimento e efetiva participação da sociedade para essa mudança de comportamento.

Fonte: Elaborado pelas autoras a partir de Jaboticabal (2014).

A partir destes objetivos, as ações estratégicas indicadas no Plano foram: a realização de palestras em instituições de ensino, fórum para debates, seminários, entrevistas em rádio e mídia impressa, com a divulgação do "cronograma semanal da coleta seletiva e orientando sobre a separação correta dos resíduos sólidos" (2014, p. 74); realização de "reuniões com os principais atores e agentes sociais da cidade com grande inserção popular como os agentes municipais de saúde, fiscais municipais com ações em meio ambiente, professores, educadores ambientais, entre outros" $(2014$, p. 74$)$ para sensibilização da sociedade em relação ao tema, buscando a minimização da geração de resíduos. Além disso, destaca a necessidade de mobilização do Poder Público Municipal para criar uma comunicação efetiva com a sociedade, por meio de: telefonemas, e-mails e convite impressos, visitas individuais, material informativo de apoio (folders, cartazes, banners, faixas, entre outros), realização de eventos com periodicidade definida ou ainda a promoção do debate por meio de fóruns já existentes nos municípios.

Todas essas ações estão definidas no Plano como processos que devem estar presente em um programa que deveria ser criado até 2015. No entanto, como o Plano ainda estava em trâmite de aprovação até meados de 2015 (quando o plano foi coletado), a criação e fortalecimento desse "programa" pode ter sido comprometido.

De acordo com as atividades propostas no artigo $8^{\circ}$, identificou-se que o PMGIRS de Jaboticabal aborda a "capacitação de recursos humanos", o "desenvolvimento de estudos, pesquisas e experimentações" e "a produção e divulgação de material educativo", porém não detalha como será feito o "acompanhamento e a avaliação" das realizações do município.

\section{Monte Alto:}


O Plano Municipal de Gerenciamento Integrado de Resíduos Sólidos de Monte Alto - SP (PMGIRS Monte Alto) faz referência às duas leis que regulamentam e orientam as diretrizes da Educação Ambiental, a Lei 12.305 de 2010 (PNRS) e a Lei 9.795 de 1999 (Política Nacional de Educação Ambiental).

O Plano afirma que

O município [...] desenvolve ações de educação ambiental mobilizando a população a entregarem seus resíduos e não depositarem em locais inadequados, assim que recolhidos os resíduos são encaminhados para um local apropriado até que se consiga uma quantidade considerável para serem entregues a uma empresa especializada no tratamento e disposição final.

Dentre essas várias ações existentes voltadas à Educação Ambiental, o Plano menciona a existência da coleta seletiva no município e a criação do Centro de Educação Ambiental, que é um local destinado a dar suporte aos conteúdos trabalhados nas escolas, um espaço de interação e contato com a natureza, e que também servirá de apoio ao Projeto "Arborização Urbana: Plante esta ideia!" realizado pelo Poder Público Municipal.

Apesar de o Plano fazer várias referências às leis, colocando-as, inclusive, na íntegra, poucas estratégias de atuação foram mencionadas. As ações mencionadas não garantem a efetiva participação e conscientização da população local, assim como não são capazes de estruturar o Plano de acordo com as atividades propostas na Lei 9.795/99.

\section{Pitangueiras:}

O Plano Municipal de Gestão Integrada de Resíduos Sólidos de Pitangueiras - SP (PMGIRS Pitangueiras) faz referência à Lei 3.071 de 2013, a qual institui a Educação Ambiental de forma transversal no ensino público municipal, além das outras duas leis já referenciadas sobre EA.

Tendo como preceito o conceito de EA dessas legislações, o Plano destaca a importância da conscientização da sociedade com a mudança de paradigmas em torno da questão de resíduos. No entanto, o PMGIRS Pitangueiras também afirma que não existia até o ano de 2013 nenhum programa de ação voltado a essa temática. E para que se efetivasse um plano algumas medidas deveriam ser tomadas, Quadro 2.

\section{Quadro 2: Medidas para criação de um Programa de Educação Ambiental em Pitangueiras-SP}

Definição de representantes da Prefeitura Municipal e da Secretaria da Agricultura, Indústria, Comércio e Meio Ambiente de Pitangueiras, que serão responsáveis pelas articulações na instância municipal para promover a mobilização e a participação da comunidade nos diversos eventos e atividades a serem planejadas;

Estabelecimento e implantação de rotinas para aprovação de projetos de educação ambiental voltados ao gerenciamento de resíduos sólidos; 


\section{ANAP

Provisão e alocação de recursos e infraestrutura para o desenvolvimento da gestão integrada do município:

\begin{tabular}{|r|}
\hline Definição e capacitação de educadores ambientais; \\
\hline Elaboração e aplicação de material didático voltado à educação ambiental; \\
\hline $\begin{array}{c}\text { Realização de palestras e oficinas sobre temas ambientais em escolas, indústrias, sindicatos, } \\
\text { associações, cooperativas e demais interessados, ministrados pelos educadores ambientais capacitados; }\end{array}$ \\
\hline
\end{tabular}

Distribuição de folders explicativos por cooperados e/ou catadores (pessoas de baixa renda) no município, contendo o itinerário das coletas de recicláveis e/ou locais dos pontos de entrega voluntária

(a serem implantados) com telefones e/ou site oficial para agendamento de coletas e conteúdo explicativo do funcionamento do sistema de gestão de resíduos sólidos do município, visando maior interação da população com o sistema em questão;

Criação de um canal de ouvidoria controlado pela Prefeitura para atendimento a sugestões e reclamações dos interessados em relação aos serviços de limpeza urbana.

Fonte: Elaborado pelas autoras a partir de Pitangueiras (2013).

Sendo que para efetivação das ações desse programa o Plano afirma que há a necessidade de participação de todos os atores envolvidos:

- A população, que deve colaborar desde o acondicionamento e a separação dos resíduos para coleta, até a participação e o engajamento nos programas;

- As indústrias e os comércios, que devem ser responsáveis pela adequada destinação de seus próprios rejeitos e pela implantação de sistemas de logística reversa para seus produtos, quando aplicável;

- As cooperativas de catadores, estruturadas com base na inclusão social de pessoas físicas de baixa renda, que, apoiadas pelo município, devem ter capacidade de atender à coleta de materiais produzidos pela população e comercializá-los para os centros de beneficiamento;

- Os estabelecimentos de saúde, que devem tratar e destinar adequadamente seus resíduos, levando em consideração os riscos sanitários e ambientais de acordo com o definido no PMGIRS;

- A prefeitura, que com seus parceiros e secretarias (Educação, Planejamento, etc.), deve atuar como protagonista do sistema. (2013, p. 95).

A partir desses pressupostos, o Plano afirma que a fiscalização e punição são medidas paliativas, sendo que o município deve investir em campanhas que conscientizem a população para que reduzam os gastos com essa atividade.

O Plano aborda a "capacitação de recursos humanos", "a produção e divulgação de material educativo" e o "acompanhamento e a avaliação", porém, não se posiciona quanto à necessidade de se "desenvolver estudos, pesquisas e experimentações". 


\section{ANAP

\section{Taquaritinga:}

O Plano Municipal de Gestão Integrada de Resíduos Sólidos de Taquaritinga (PMGIRS Taquaritinga) apresenta a necessidade da elaboração de um Programa de Educação Ambiental (dentre outros planos e programas) para a expedição de uma Licença de Instalação junto à CETESB (Companhia Ambiental do Estado de São Paulo). Além disso, para a realização de um Programa de Coleta Seletiva adequado, o PMGIRS Taquaritinga afirma ser importante conhecer a viabilidade econômica, ter infraestrutura adequada e elaborar um Plano de Educação Ambiental.

Partindo dessas justificativas, o Plano propõe a implantação de um Parque Eco Industrial (PEI), o qual, dentre outras atribuições, incluirá um "centro de educação ambiental com a existência de uma sala de aula climatizada e com capacidade para 40 alunos" ( 2014, p. 165). Além disso, há a proposta de criação de um pátio de compostagem em área anexa ao $\mathrm{PEI}$, próximo ao aterro municipal, para que a prática de reaproveitamento dos resíduos possa ser vista por todos do Parque.

É possível identificar também, no PMGIRS Taquaritinga, a importância de promoção da Educação Ambiental no descarte de pneus, de resíduos da construção civil, da indústria e da população rural. Bem como estimular o envolvimento de crianças, jovens, adultos e idosos, "buscando a mudança de hábitos de geração, armazenagem e descarte de resíduos sólidos". (2014, p. 199).

Por fim, o Plano estipula valores monetários a serem desembolsados, pelo Poder Público Municipal, até 2034 para a realização de campanhas de educação ambiental (Quadro 3). 


\section{ANAP \\ Brasil \\ ISSN 1984-3240 \\ V. 9, n. 14}

Quadro 3: Valores a serem gastos com campanhas de Educação Ambiental em Taquaritinga

\begin{tabular}{|c|r|}
\hline Ano & Meta (em R\$) \\
\hline 2017 & $180.000,00$ \\
\hline 2022 & $300.000,00$ \\
\hline 2026 & $300.000,00$ \\
\hline 2034 & $300.000,00$ \\
\hline
\end{tabular}

Fonte: Elaborado pelas autoras a partir de Taquaritinga (2014).

É possível perceber que apesar de serem especificados valores para investimento em campanhas de Educação Ambiental, não foram definidas estratégias de ação, ou sequência metodológica a ser adota. Neste Plano, evidenciou-se, com ênfase, a importância do Parque Eco Industrial na promoção da EA, mas pouco se falou sobre os objetivos de EA para o município, sobre a conceituação da temática para o Poder Público e sobre a legislação de referência da Educação Ambiental. Dessa forma, as diretrizes do Plano Nacional de Educação Ambiental não ficam plenamente atendidas.

\section{CONCLUSÃO}

Identificou-se que nenhum município atende integralmente, nos textos de seus Planos Municipais, aos preceitos da PNRS sobre Educação Ambiental.

O Plano Intermunicipal de Bebedouro, devido à falta de informações, deixa dúvidas sobre como será desenvolvido o tema neste município e em seu consorciado. Porém, em suma, o único critério não abordado pelo Plano é o que se refere aos "estudos, pesquisas e experimentações" ditado pela Política Nacional de Educação Ambiental.

Guariba, Monte Alto e Taquaritinga não abordam com precisão nenhum dos quatro critérios descritos no artigo 8 o, pois trazem informações insipientes e vagas a respeito das ações a serem tomadas. $O$ que reflete que o tema não foi abordado com seriedade e embasamento legal.

Os demais, Jaboticabal e Pitangueiras, têm em comum o relato de suas atividades quanto aos critérios de "capacitação de recursos humanos" e "produção e divulgação de material educativo". Jaboticabal não se posiciona quanto ao critério de "acompanhamento e a avaliação", o que dificultará identificar os gargalos e a evolução do PMGIRS. Por sua vez, Pitangueiras não trata do critério "desenvolver estudos, pesquisas e experimentações", o que poderá não gerar conhecimento sobre a situação dos resíduos sólidos e das formas de consumo no município, dentre outros.

Conclui-se que, a aplicação e perpetuidade da PNRS pode estar comprometida nestes municípios, pois um dos temas mais relevantes para a efetivação e manutenção desta Política é a Educação Ambiental, por gerar conhecimento sobre a questão ambiental e os resíduos sólidos na e para a sociedade como um todo. 


\section{AGRADECIMENTOS}

As autoras agradecem aos órgãos municipais que se dispuseram prontamente a enviar os respectivos Planos, alvo das análises deste artigo.

\section{REFERÊNCIAS BIBLIOGRÁFICAS}

ANDRADE, D. F.; LUCA. A. Q.; CASTELLANO, M.; RISSATO, C.G.; SORRENTINO, M. Da pedagogia à política e da política à pedagogia: uma abordagem sobre a construção de políticas públicas em educação ambiental no Brasil. Ciênc. Educ., Bauru, v. 20, n. 4, p. $817-832,2014$.

BRASIL. Lei $n^{\circ}$ 9.795, de 27 de abril de 1999. Dispõe sobre a educação ambiental, institui a Política Nacional de Educação Ambiental e dá outras providências. Diário Oficial [da] República Federativa do Brasil, Brasília, DF. 1999. Disponível em: < http://www.mma.gov.br/port/conama/legiabre.cfm?codlegi=321> Acesso em 16 de Abr. 2016.

. Lei $n^{\circ} 12.305$, de 2 de agosto de 2010. Institui a Política Nacional de Resíduos Sólidos; altera a Lei $n^{\circ} 9.605$, de 12 de fevereiro de 1998; e dá outras providências. Diário Oficial [da] República Federativa do Brasil, Brasília, DF. 2010a. Disponível em: <http://www.planalto.gov.br/ccivil_03/_ato2007-2010/2010/lei/l12305.htm> Acesso em 15 Abr. 2016.

. Decreto $n^{\circ}$. 7.404, de 23 de Dezembro de 2010. Regulamenta a Lei $n^{\circ}$ 12.305, de 2 de agosto de 2010, que institui a Política Nacional de Resíduos Sólidos, cria o Comitê Interministerial da Política Nacional de Resíduos Sólidos e o Comitê Orientador para a Implantação dos Sistemas de Logística Reversa, e dá outras providências. Diário Oficial [da] República Federativa do Brasil, Brasília, DF. 2010b. Disponível em: < http://www.planalto.gov.br/ccivil_03/_ato2007-2010/2010/Decreto/D7404.htm > Acesso em: 15 Abr. 2016.

BEBEDOURO. SIGEINRES - Consórcio Intermunicipal para a Gestão Integrada de Resíduos Sólidos. Plano de Saneamento de Resíduos Sólidos e Manejo de Resíduos. Barretos - SP, 2011. 128 f.

GUARIBA. Prefeitura Municipal de Guariba. Plano Integrado de Gestão de Resíduos Sólidos de Guariba - SP, Guariba - SP, 2014. 139 f.

JABOTICABAL. Prefeitura Municipal de Jaboticabal. SAAEJ - Serviço Autônomo de Água e Esgoto de Jaboticabal e SAAMA - Secretaria de agricultura, abastecimento e meio ambiente de Jaboticabal. Plano Municipal de Gestão Integrada de Resíduos Sólidos de Jaboticabal, Jaboticabal - SP, 2015. 97 f.

JACOBI, P. Educação ambiental, cidadania e sustentabilidade. Cadernos de Pesquisa, n. 118, p. 189 - 205. 2003.

MONTE ALTO. Plano Municipal de Gerenciamento Integrado de Resíduos Sólidos de Monte Alto - SP. Monte Alto -SP, 196 f. (Elaborado por PROJECTA, Assessoria e Consultoria)

PITANGUEIRAS. Plano Municipal de Gestão Integrada de Resíduos Sólidos de Pitangueiras/SP. Pitangueiras - SP, 2013. 105 f. (Elaborado por SANETECH. Sanetech Engenharia e Meio Ambiente Ltda).

TAQUARITINGA. Prefeitura Municipal de Taquaritinga. Plano Municipal de Gestão Integrada de Resíduos Sólidos PMGIRS, Taquaritinga - SP, 2014. $231 \mathrm{f}$. 